\title{
Research on Consumer Risk Perception and Trust Transmission between Channels
}

\author{
Eugenio Gibbert ${ }^{1}$ and Roberto Cavalletti ${ }^{2}$ \\ ${ }^{1,2}$ Department of Economics, Università degli Studi di Genova, Genoa, Italy \\ 1eugenio.gibbertt@gmail.com
}

\begin{abstract}
Based on the theoretical foundation of empirical research on online consumer trust, this paper establishes a mathematical model of trust transmission between channels. Consider that a manufacturer sells products offline through an independent retailer, while the manufacturer expands offline products to direct online channels, and establishes trust transmission between offline and online channels to achieve channel synergy. In channel pricing, the full price theory of the channel is used to establish a model to study the issue of trust transmission between channels. Based on the different perceived risks of online and offline consumers, the issue of trust transmission and pricing between channels is studied. Taking the online consumer trust of channel expansion as the object, constructing the consumer utility function under the influence of perceived risk and the degree of online trust, and establishing the Stackelberg game model. The relationship between channel pricing and online trust level and the main determinants of trust transmission between channels are discussed. The research results show that the increase in online trust leads to a decrease in offline pricing, a decrease in offline demand, and an increase in online demand, and the profits of manufacturers increase while the profits of retailers decrease. Also, manufacturers' efforts to transmit trust in online channels decrease with the increase in offline product performance fluctuations, decrease with the increase in trust transmission cost coefficient, and increase with the increase in offline and online cost gaps.
\end{abstract}

Keywords: Consumer behavior, Risk perception, Trust level, Channel

\section{Introduction}

In the context of new retail, online companies, offline traditional consumer goods retail companies, and various cross-border corporate giants are actively trying to expand retail channels and form a sales model that combines multiple channels. Online shopping has time and price advantages, but compared with physical stores, consumers' perceived risk is still high. The lack of sufficient consumer trust is currently the biggest obstacle to the development of online transactions [1]. Consumers' shopping channel choice is often a trade-off between product price, shopping time, delivery time, and perceived risk. Their willingness to pay for different channels is a function of time, convenience, and risk cost, and depends on the characteristics of consumer preferences. Change [2]. Consumer behavior determines the choice of shopping channels, and personal risk-taking behavior often depends on their perception of risk and the degree of risk acceptance [3], so the risk will affect consumer shopping channel selection behavior. Consumers feel risk in most purchase decisions, and risk perception greatly

Article history:

Received (December 25, 2020), Review Result (January 29, 2021), Accepted (March 4, 2021) 
affects consumer purchase decisions, leading to changes, delays, or abandonment of purchases [4][5]. The inherent intangibility of the online environment and face-to-face contact with a nonpersonnel lead to greater consumer perceived risks. When there is uncertainty in products or services, relatively speaking consumers with low-risk aversion prefer online shopping, while consumers with high-risk aversion prefer physical stores [6]. In addition to providing convenient purchasing methods and preferential prices for online companies, how to meet consumers' psychological needs is more important.

Some scholars have found that because trust has a positive impact on consumers, it can be used in an effective risk reduction mechanism [7][8]. The level of trust in online shopping continues to grow, but it is still low relative to offline sales [9]. The key way to solve this online trust establishment problem is trust transfer, which builds a positive perception of the integrity of online stores through trust in physical stores that consumers are familiar with. The combination of online and offline channels can certainly use physical storefronts to save costs in terms of warehousing, transportation, and distribution. More importantly, it can use the trust established by consumers in offline physical stores to solve online consumers' lack of trust and perceived risk. High question. For most online transactions, it is more difficult to gain user trust. It can be inferred that online companies with offline businesses have certain advantages in enhancing consumer trust. For offline companies, the problem they face when expanding online channels is whether the trust of offline consumers accumulated over the years can be transferred to consumers' good perception of online products.

The literature on online trust is mainly to verify the determinants of trust establishment from an empirical point of view, as well as the influence of individual factors on trust transfer [9]. McKnight and Chervany [11] classified the trust in the online context and identified the three dimensions of online trust, namely, preference trust (such as general trust tendency); systembased trust (such as trust in the Internet environment); Interpersonal trust (such as trust in online product suppliers). Stewart [12] studied the influence of links between multiple websites on trust transfer between websites in an online context. The study believes that the more mutual links between websites, the higher the relevance and quality of the links, the more significant the phenomenon of trust transfer. Kuan and Bock [13] revealed through empirical research that consumers' trust in retailers' offline businesses will enhance their trust in online businesses. Kuan and Bock believe that consumers will rely on the consumption experience of online retailers' physical stores to build trust, and offline trust, social network word-of-mouth, and expected sanctions against merchants' breaches of trust are the most significant factors in establishing online consumer trust. Elements. Lee et al. [14] verified through empirical research that consumers' trust in offline banks will affect their adoption of bank online business. It is proposed that the trust in offline banks will directly affect online banking from four aspects: structural guarantee, liquidity, perceived website satisfaction, and perceived usage. Bock et al. [15] evaluated the influencing factors of online trust of multi-channel retailers at different stages and empirically revealed the transfer of trust of multi-channel retailers from offline channels to online channels. Schijndel et al [16] puts forward a model of influencing factors of online retail consumption willingness based on trust theory and perceived risk and empirically reveals the relationship between online retailer's brand image, sales management, service quality, technical safety, and consumers' trust tendency and perceived risk. Zhang et al [17] regards the dealer as the first customer of the enterprise and explores the mechanism of customer trust and transfer barriers on customer retention in the B2B scenario through case studies. Zeng et al [19] discussed the process of trust restoration after channel member conflicts, analyzed the influence of different restoration strategies (cooperative strategies and competitive strategies) on trust restoration, and tested the mediating role of perceived fairness (procedural 
fairness and distribution fairness). Larson [20] empirically studies the influence of unfair and speculative behavior in channels on channel cooperation based on a destructive perspective and analyzes the mediating role of organizational trust and conflict in the above effects.

The literature that studies trust transfer between channels mainly verifies the positive effect of offline channel consumer trust on the establishment of online trust from an empirical point of view, and the main determinants of online trust establishment. Similar to offline interaction, the trust goal of online transactions is also to try to present consumers with trustworthy objects [21]. To establish themselves as trustworthy objects, online organizations must strive to improve their reputation, performance, and interface design. At the same time, online consumers evaluate the trustworthiness of their online transaction objects based on standards of competitiveness, ethics, and integrity. In addition, the issues that companies will also involve in channel expansion include: How will the differences in consumer perception of risks between online and offline shopping methods affect channel pricing? How does the establishment of trust affect the pricing of channel products? How to influence consumers' choices of shopping methods? In the process of trust transfer from offline to online, how much effort does the manufacturer put in to establish the trust of online consumers and reduce the perceived risk? What factors affect the level of trust transmission between channels? Based on the theoretical foundation of predecessors' empirical research on online consumer trust, this paper establishes a mathematical model of trust transmission between channels. Consider that a manufacturer sells products offline through an independent retailer, while the manufacturer expands offline products to direct online channels, and establishes trust transmission between offline and online channels to achieve channel synergy. In channel pricing, the full price theory of channels [22] is used to establish a model to study the issue of trust transmission between channels and to discuss the above issues.

\section{Consumer risk perception and trust transfer model and assumptions}

Manufacturers sell products through both online and offline channels, and offline sales of products in physical stores through retailers; at the same time, manufacturers establish online sales channels to sell products directly online. Due to the low overall authenticity rate of electronic channels, although the products sold by manufacturers online are authentic, consumers feel that the risk is higher because they cannot touch the physical products during shopping, that is, the perceived risk is higher. Let $U(I)$ denote the consumer's utility function at the time of the current property (that is, what to do to buy). It is assumed that the consumer utility function is expressed as a constant relative risk aversion (CARA). Let $v$ denote the consumer's risk appetite. The Arrow-Pratt measurement of this risk aversion is $v=-\frac{U^{\prime \prime}(I)}{U^{\prime}(I)}=$ $-\frac{d \ln U^{\prime}(I)}{d I}$ 。The corresponding exponential utility function is $U(I)=-e^{-v I}$ 。

When consumers shop in offline physical stores, the benefits obtained through product purchase $B=\theta \pm \sigma, \theta$ is the expected benefit of consumers buying this product, and $\sigma$ is the fluctuation of benefit, which depends on the stability of product quality and function. The more stable the product quality function, the smaller the $\sigma$. Due to risk aversion, consumers will have perceived risk $(v / 2) \cdot \sigma^{2}$ during the purchase process. Given that the products sold online and offline are the same, but because consumers cannot access the actual products during online consumption and transactions are completed through humans and machines, their perceived risks are greater. For consumers, the perceived risk is $(v / 2) \cdot(\sigma / \gamma)^{2}$. Among them, $\gamma$ is the trust transfer coefficient of offline to online products formed when manufacturers expand their products from offline channels to online channels. Since consumers of online products cannot 
directly experience products and services, online transactions aggravate consumer risks. Therefore, given here $\gamma \in(0,1)$, it means that consumers will think in terms of psychological perception during online shopping Compared with the offline shopping method, it takes a greater risk. The greater the trust transfer coefficient, the more effective the establishment of trust transfer from offline to online enterprise products, and the lower the perceived risk of consumers during online shopping.

As online shopping consumers face greater perceived risks, only consumers with a relatively low degree of risk aversion will purchase products through online channels [22]. If $v_{2}>v_{1}$, a consumer with a risk preference factor of $v_{2}$ will show a greater degree of risk aversion than a consumer with a risk preference factor of $v_{1}$. Marginal consumers are equally effective in purchasing products online and offline. When $U_{r}>U_{d}$, using the deterministic equivalence method, when the risk premium is included, the critical point for the equal utility of the two methods is $\theta-\frac{v_{1}}{2} \sigma^{2}-p_{\mathrm{r}}=\theta-\frac{v_{1}}{2}\left(\frac{\sigma}{\gamma}\right)^{2}-p_{\mathrm{d}}$ 。 where, $p_{\mathrm{r}}$ is the price of the company's offline product; $p_{\mathrm{d}}$ is the price of the company's online product. Simplify the above expression, get

$$
v_{1}=2 \gamma^{2} \frac{p_{r}-p_{d}}{\left(1-\gamma^{2}\right) \sigma^{2}}
$$

where, when $v<v_{1}$, there must be $U_{r}<U_{d}$, and the consumer's risk aversion degree is not high. At this time, due to the lower online price, the utility of online shopping will be greater than the utility of offline shopping. Therefore, in the interval $\left[0, v_{1}\right]$, consumers purchase online.

When the degree of risk aversion is greater than $v_{1}$, at this time $U_{r}>U_{d}$, consumers choose offline shopping, and when it reaches, the utility of buying products and not buying is equivalent, $U_{r}=U_{0}=0$, get $\theta-p_{r}-\frac{v_{2}}{2} \sigma^{2}$, so you can get $v_{2}=\frac{2\left(\theta-p_{\mathrm{r}}\right)}{\sigma^{2}}$ 。 The total product demand interval is $\left[0, v_{2}\right]$, That is

$$
\mu=v_{2}=\frac{2\left(\theta-p_{r}\right)}{\sigma^{2}}
$$

Equation (1) means that the demand for a product not only depends on its utility $\theta$ and the selling price $p_{r}$, but is also affected by the product quality: the smaller $\sigma$, the more stable the product quality, the greater the corresponding product demand $\mu$, and vice versa The smaller the demand. This is very consistent with reality. Therefore, the online channel demand is

$$
q_{d}=v_{1}=2 \gamma^{2} \frac{p_{r}-p_{d}}{\left(1-\gamma^{2}\right) \sigma^{2}}
$$

The demand for offline channels is

$$
q_{r}=v_{2}-v_{1}=2 \frac{\left(1-\gamma^{2}\right) \theta-p_{r}+\gamma^{2} p_{d}}{\left(1-\gamma^{2}\right) \sigma^{2}}
$$

Assume that the unit cost of offline sales is $c_{\mathrm{r}}$, and the unit cost of online sales is $c_{\mathrm{r}}>c_{\mathrm{d}}$, that is, offline sales face greater costs. In the process of trust transmission between product channels, a lot of effort or investment is required, including effective publicity, consumer behavior guidance, a large amount of advertising investment, and so on. Assume that the cost paid by the manufacturer for online trust establishment is $C=I /\left(1-\gamma^{2}\right)$, where $\gamma$ is the product trust transfer coefficient; $I$ is the trust transfer cost coefficient. The greater the coefficient of trust transfer cost, the more difficult it is to establish the trust of consumers from 
offline to online, the greater the effort required, and the greater the cost. Therefore, the profit of offline channel retailers is

$$
\pi_{r}=\left(p_{r}-w-c_{r}\right) \cdot 2 \frac{\left(1-\gamma^{2}\right) \theta-p_{r}+\gamma^{2} p_{d}}{\left(1-\gamma^{2}\right) \sigma^{2}}
$$

The manufacturer's profit is

$$
\pi_{m}=w \cdot 2 \frac{\left(1-\gamma^{2}\right) \theta-p_{r}+\gamma^{2} p_{d}}{\left(1-\gamma^{2}\right) \sigma^{2}}+\left(p_{d}-c_{d}\right) \cdot 2 y^{2} \frac{p_{r}-p_{d}}{\left(1-\gamma^{2}\right) \sigma^{2}}-\frac{I}{1-\gamma^{2}}
$$

The decision sequence is as follows. In the first stage, the manufacturer determines the degree of trust transfer between channels $\gamma$. In the second stage, manufacturers and retailers conduct price games within channels to determine channel pricing. In the channel price decision, the manufacturer first determines the offline channel wholesale price $w$ and the online channel product price $p_{d}$, and the retailer determines the offline channel product retail price $p_{r}$.

\section{Pricing decision}

Under the condition that the degree of trust transmission between channels $\gamma$ is established, the second-stage manufacturer and the retailer conduct a channel price game. Given that the upstream manufacturer determines the offline wholesale price $w$ and the online price $p_{d}$ of the product, the retailer determines the product line, the retail price is $\mathrm{p} \_\mathrm{r}$ to maximize its profit, that is, $p_{r}^{*}=\operatorname{argmax}_{r}\left(p_{r}\right)$. From equation (4) the first-order condition of retailer's profit on pricing, which is $d \pi_{r} / d p_{r}=0$, get $\frac{d \pi_{r}}{d p_{r}}=2 \cdot \frac{\left(1-\gamma^{2}\right) \theta-2 p_{r}+w+c_{r}+\gamma^{2} p_{d}}{\left(1-\gamma^{2}\right) \sigma^{2}}$, Given $w$ and $p_{d}$ for downstream retailers, the offline price of the product is

$$
p_{r}=\frac{\left(1-\gamma^{2}\right) \theta+\gamma^{2}\left(c_{d}+p_{d}\right)-c_{r}+w}{2}
$$

Substituting $p_{r}$ into formula (5) the manufacturer's profit function, we get

$$
\pi_{m}=w \cdot \frac{\left(1-\gamma^{2}\right) \theta-w-c_{r}+\gamma^{2} p_{d}}{\left(1-\gamma^{2}\right) \sigma^{2}}+\left(p_{d}-c_{d}\right) \cdot \gamma^{2} \frac{\left(1-\gamma^{2}\right) \theta+w+c_{r}-\left(2-\gamma^{2}\right) p_{d}}{\left(1-\gamma^{2}\right) \sigma^{2}}
$$

According to formula (7), the manufacturer's profit is the first-order condition of product offline retail pricing $w$ and product online pricing $p_{d}$ respectively, that is $\frac{\mathrm{d} \pi_{\mathrm{m}}}{\mathrm{d} p_{\mathrm{d}}}=0$, get

$$
\begin{gathered}
\frac{d \pi_{m}}{d w}=\frac{\left(1-\gamma^{2}\right) \theta-2 w-c_{r}+\gamma^{2} p_{d}}{\left(1-\gamma^{2}\right) \sigma^{2}}+\frac{\left(p_{d}-c_{d}\right) \cdot \gamma^{2}}{\left(1-\gamma^{2}\right) \sigma^{2}} \\
\frac{d \pi_{m}}{d p_{d}}=\frac{\gamma^{2} w}{\left(1-\gamma^{2}\right) \sigma^{2}}+\gamma^{2} \frac{\left(1-\gamma^{2}\right) \theta+w+c_{r}-\left(2-\gamma^{2}\right)\left(2 p_{d}-c_{d}\right)}{\left(1-\gamma^{2}\right) \sigma^{2}}
\end{gathered}
$$

Simultaneous formula (8) and formula (9), get $p_{d}^{*}=\frac{\theta+c_{d}}{2} w^{*}=\frac{\theta-c_{d}}{2}$, Get from $p_{d}^{*}$ and $w^{*}$

$$
p_{r}^{*}=\frac{\left(3-\gamma^{2}\right) \theta+c_{r}+\gamma^{2} c_{d}}{4}
$$


Proposition 1. The offline retail price $p_{r}^{*}$ of the product decreases with the increase of the trust transfer coefficient $\gamma$.

Prove : From equation (10) $p_{r}^{*}$ Derivation of the trust transfer coefficient $\gamma$ can be obtained $\frac{d p_{r}^{*}}{d \gamma}=\frac{-2 \gamma \theta+2 \gamma c_{\mathrm{d}}}{4}$, And because where $\theta>c_{d}$, From this you can get $\frac{d p_{r}^{*}}{d \gamma}<0$, Proposition 1 is proved.

Proposition 1 shows that in the process of simultaneous offline and online dual-channel product sales if the offline to online trust transfer coefficient is large, it indicates that consumers have less perceived risk of online sales of the company, which is beneficial to the company at this time Online product sales. Then, among the online and offline choices, some consumers tend to choose online shopping. Since offline retail prices are set by retailers, they must lower prices to maintain competition with online channels. In comparison, when consumers choose offline shopping, their perceived risk is relatively small. When the online trust of the product is successfully established and consumers' perceived risk can be reduced, this will inevitably squeeze the profit space of offline retailers. Forcing it to reduce product prices.

Substituting further, we can get the product online channel demand in equilibrium as

$$
q_{d}^{*}=\gamma^{2} \frac{\left(1-\gamma^{2}\right) \theta+c_{r}-\left(2-\gamma^{2}\right) c_{d}}{2\left(1-\gamma^{2}\right) \sigma^{2}}
$$

Offline demand is

$$
q_{r}^{*}=\frac{\left(1-\gamma^{2}\right) \theta-c_{r}+\gamma^{2} c_{d}}{2\left(1-\gamma^{2}\right) \sigma^{2}}
$$

It can be seen from equations (11) and (12) that the online demand and offline demand of products are related to the trust transfer coefficient between channels, and the propositions obtained are as follows.

Proposition 2 "Online product consumption $q_{\mathrm{d}}^{*}$ demand increases with the trust transfer coefficient; offline product consumption demand $q_{\mathrm{r}}^{*}$ decreases with the trust transfer coefficient $\gamma$.

Prove: due to

$$
q_{d}^{*}=\gamma^{2} \frac{\left(1-\gamma^{2}\right) \theta+c_{r}-\left(2-\gamma^{2}\right) c_{d}}{2\left(1-\gamma^{2}\right) \sigma^{2}}=\gamma^{2} \frac{\theta-c_{d}+\frac{c_{r}-c_{d}}{1-\gamma^{2}}}{2 \sigma^{2}}
$$

where, $\quad c_{\mathrm{r}}-c_{\mathrm{d}}>0$. And since $\gamma \in(0,1), q_{\mathrm{d}}^{*}$ increases with $\gamma$. The same, due to

$$
q_{\mathrm{r}}^{*}=\frac{\left(1-\gamma^{2}\right) \theta-\left(1-\gamma^{2}\right) c_{\mathrm{d}}+c_{\mathrm{d}}-t_{\mathrm{r}}}{2\left(1-\gamma^{2}\right) \sigma^{2}}=\frac{\theta-c_{\mathrm{d}}-\frac{c_{\mathrm{r}}-c_{\mathrm{d}}}{1-\gamma^{2}}}{2 \sigma^{2}},
$$

$q_{\mathrm{d}}^{*}$ increases with the increase of $\gamma$, and $q_{\mathrm{r}}^{*}$ decreases with the increase of $\gamma$. Proposition 2 is proved.

Increasing $\gamma$ means that consumers' trust in online channels increases, and the perceived risk of shopping decreases. When the online channel trust of a product is successfully established, consumers' tendency to consume online will increase, which will inevitably lead to an increase in consumer demand for online products, and accordingly, the demand for offline products will decrease.

Furthermore, it can be obtained that under a given situation, the manufacturer's profit is 


$$
\pi_{m}^{*}=\frac{\left(1-\gamma^{2}\right)\left(\theta-c_{r}\right)^{2}+\gamma^{2}\left(1-\gamma^{2}\right)\left(\theta-c_{d}\right)^{2}+\gamma^{2}\left(c_{d}-c_{r}\right)^{2}}{4\left(1-\gamma^{2}\right) \sigma^{2}}-\frac{I}{1-\gamma^{2}}
$$

The retailer's profit is

$$
\pi_{r}^{*}=\frac{\left[\left(1-\gamma^{2}\right) \theta-c_{r}+\gamma^{2} c_{d}\right]^{2}}{8\left(1-\gamma^{2}\right) \sigma^{2}}
$$

Derivation of the manufacturer's profit versus the trust transfer coefficient $\gamma$ in equation (13), we get

$$
\frac{d \pi_{m}^{*}}{d y}=\frac{2 \gamma\left(\theta-c_{d}\right)^{2}}{4 \sigma^{2}}+\frac{2 \gamma\left(c_{r}-c_{d}\right)^{2}}{4\left(1-\gamma^{2}\right)^{2} \sigma^{2}}-2 I \gamma
$$

In formula (15) $\frac{d \pi_{m}^{*}}{d \gamma}=0$, under the equilibrium situation, when the manufacturer establishes an online channel for the product, the determined optimal trust transfer coefficient is

$$
\gamma^{*}=\sqrt{1-\sqrt{\frac{4 \sigma^{2} I-\left(c_{r}-c_{d}\right)^{2}}{\left(\theta-c_{d}\right)^{2}}}}
$$

where, $\gamma^{*}$ is the trust transfer coefficient between channels selected by the manufacturer when expanding online channels.

\section{Discussion of results}

In the discussion of the results, the paper will discuss the value of $\gamma^{*}$ under equilibrium decision-making to determine the relationship between the online and offline trust transfer coefficient and the degree of risk, investment cost coefficient, channel cost, and the profit of manufacturers and retailers in the supply chain.

When $\left[\left(\theta-c_{d}\right)^{2}+\left(c_{r}-c_{d}\right)^{2}\right] / 4 \sigma^{2}>1>\left(c_{r}-c_{d}\right)^{2} / 4 \sigma^{2}$, it can be ensured that $\gamma^{*}$ is the interior point solution within the value range $\gamma \in(0,1)$. At this time, $\gamma^{*}$ is the trust transfer coefficient between channels under equilibrium conditions; when $\gamma^{*}$ has interior-point solutions, the following conclusions can be obtained from the expression of $\gamma^{*}$.

(1) $d \gamma^{*} / d \sigma<0, \quad \gamma^{*}$ decreases with the increase of $\sigma$. This means that when manufacturers establish trust transmission from offline channels to online channels, their efforts and motivation will be affected by the quality of their products. If the manufacturer's product quality is high, there will be greater efforts and motivation to invest in the trust of online consumers; otherwise, the motivation to invest will decline. In fact, among the successful manufacturers that have established offline to online, such as Samsung and Haier, the success of their offline to online channel expansion is due to the relatively stable quality of their products. The smaller the $\sigma$, the stronger the consumers' trust in the offline quality of the product. Therefore, the decrease of $\gamma^{*}$ with the increase of $\sigma$ also verifies that the establishment of trust in offline channels has a positive effect on trust in online channels. The main empirical results in the trust transmission literature.

(2) $d \gamma^{*} / d I<0, \quad \gamma^{*}$ decreases with the increase of $I$. When establishing consumer trust in online websites, manufacturers can work hard to guide the transfer of consumer trust, build online channels, maintain original customer loyalty, and improve online consumer satisfaction in each transaction. When reaching the same trust establishment coefficient, if the cost factor 
is larger, the cost will be higher. The high cost will affect the manufacturer's effort and motivation to establish online trust.

(3) $d y^{*} / d\left(c_{r}-c_{d}\right)>0, \quad \gamma^{*}$ increases with the increase of $\left(c_{r}-c_{d}\right)$, indicating that the greater the physical channel cost, the more successful the online channel cost savings, the more motivated the manufacturer to establish a higher consumer trust transfer coefficient. This is because $c_{r}>c_{d}$. When $\left(c_{r}-c_{d}\right)$ is larger, it means that online channels have more obvious cost advantages over offline channels. For manufacturers, they have more motivation to increase consumer trust in online channels and let consumers choose Online shopping.

When $I>\left[\left(\theta-c_{\mathrm{d}}\right)^{2}+\left(c_{\mathrm{r}}-c_{\mathrm{d}}\right)^{2}\right] / 4 \sigma^{2}$, it can be seen from equation (15) that $\frac{d \pi_{m}^{*}}{d \gamma}<0$ is always satisfied in the interval of $\gamma \in(0,1)$, which means that the profit decreases with increasing. In this case, the cost of establishing trust in online channels is too high. The smaller the trust transfer coefficient determined by the manufacturer, the better, and the manufacturer will give up efforts to establish online consumer trust.

When $I<\left(c_{\mathrm{r}}-c_{\mathrm{d}}\right)^{2} / 4 \sigma^{2}$, it can be seen from formula (15) that $\frac{d \pi_{m}^{*}}{d \gamma}>0$ is always satisfied in the $\gamma \in(0,1)$ interval, which means that the profit increases with the increase of $\gamma$. In this case, the cost of establishing trust in online channels is not high, and the greater the trust transfer coefficient determined by the manufacturer, the better so that consumers' confidence in online shopping and offline shopping will be as similar as possible to reduce consumers' perceived risks online.

Furthermore, in the numerical simulation, the correlation analysis of the trust transfer coefficient $\gamma$ formed by expanding the product from offline channels to online channels by each parameter is performed, and the parameters are shown in [Table 1].

Combining the changes of the parameters given in Table 1 with the trust transfer coefficient, [Figure 1] depicts the changes of each parameter in the $\gamma \in(0,1)$ interval and expresses the relationship between each parameter and the trust transfer coefficient.

Table 1. Variation of parameters with trust transfer coefficients $\gamma$

\begin{tabular}{|c|c|c|c|c|c|c|c|c|}
\hline \multirow{2}{*}{ variable } & \multicolumn{9}{|c|}{$\mathrm{r}$} \\
\cline { 2 - 9 } & 0.1 & 0.2 & 0.3 & 0.4 & 0.5 & 0.6 & 0.7 & 0.8 \\
\hline$p_{r}^{*}$ & 1 & 1.79 & 2.6 & 3.3 & 3.9 & 4.6 & 5.1 & 5.51 \\
\hline$q_{d}^{*}$ & -1 & -0.4 & 0.2 & 0.8 & 1.4 & 2.1 & 2.6 & 2.67 \\
\hline$q_{r}^{*}$ & -0.01 & 1.08 & 1.6 & 1.8 & 1.8 & 1.7 & 1.6 & 1.2 \\
\hline$\pi_{m}^{*}$ & 0.01 & 0.51 & 1.6 & 2.9 & 4.5 & 6.4 & 8.5 & 11 \\
\hline$\pi_{r}^{*}$ & 0 & 0.2 & 0.5 & 0.8 & 1 & 1 & 0.7 & 0.38 \\
\hline
\end{tabular}




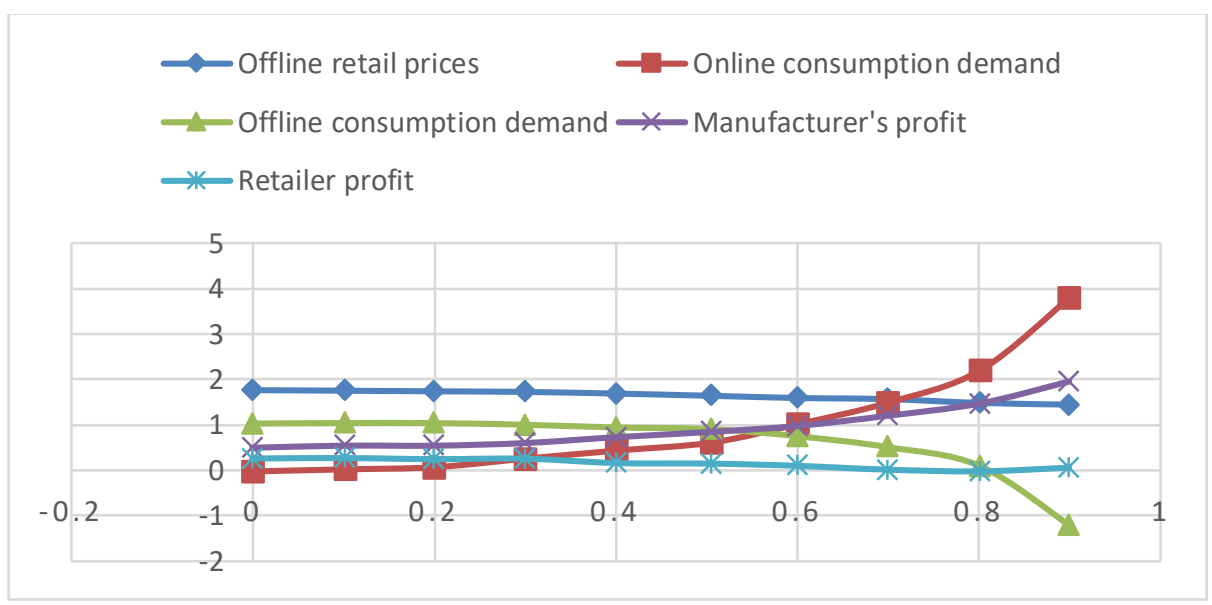

Figure 1. Variation of parameters under different trust transfer coefficients $\gamma$

Combining [Table 1] and [Figure 1], it can be seen that as the trust transfer coefficient increases, consumers' risk perception decreases, and the offline retail price $p_{r}^{*}$ gradually decreases to attract consumers, which verifies the conclusion of Proposition 1 in the article. At the same time, online product consumption demand $q_{\mathrm{d}}^{*}$ and trust transfer coefficient $\gamma$ have a positive correlation change relationship, and offline product consumption demand $q_{\mathrm{r}}^{*}$ and $\gamma$ have a negative correlation change relationship. When $\gamma$ increases, consumers flow online to consume, which verifies Proposition 2 in the article. The manufacturer's profit $\pi_{\mathrm{m}}^{*}$ increases with the increase of the offline-to-online trust transfer coefficient $\gamma$, and the retailer's profit $\pi_{\mathrm{r}}^{*}$ decreases with the increase of the trust transfer coefficient $\gamma$, which verify the result of Proposition 2 in the article.

\section{Conclusion}

The establishment of product online trust has become a key element of the success of its online sales. This article constructs the consumer utility function under the influence of perceived risk and online trust level, discusses how the difference in consumer perception of risk between online and offline shopping methods will affect channel pricing, and how the establishment of trust affects channel product price pricing. On this basis, it further analyzes the relationship between online and offline trust transfer coefficient and risk degree, investment cost coefficient, channel cost, and profit of manufacturers and retailers in the supply chain. The following conclusions of different channel models may have some changes, but this article can provide a theoretical model for the study of channel trust transmission and provide ideas for exploration. At the same time, the future research of this article can include: comparing different channel modes, under the influence of perceived risk and consumer trust, the profit changes of each member in the channel, and discussing how to choose the channel mode under the influence; perceived risk and trust. In addition, to further understand the consumer experience or the process of shopping, to discuss consumer behavior, channel members' price decisions, and channel model choices under the trade-off of shopping time, waiting time, perceived risk, and product price. 


\section{References}

[1] K. Kim and J. Y. Kim, "Third-party privacy certification as an online advertising strategy: An investigation of the factors affecting the relationship between third-party certification and initial trust," Journal of Interactive Marketing, vol.25, no.3, pp.145-158, (2011)

[2] D. Grewal, "Strategic online and offline retail pricing: A review and research agenda," Journal of Interactive Marketing, vol.24, no.2, pp.138-145, (2010)

[3] D. Kahneman, P. Slovic, and A. Tversky, "Judgment under uncertainty: Heuristics and biases," Cambridge: Cambridge University Press

[4] G. Mortimer, S. Muhammad, M. Grimmer, and L. Grimmer, "Explaining the impact of consumer religiosity, perceived risk and moral potency on purchase intentions," Journal of Retailing and Consumer Services, vo 1.55, (2020)

[5] C. Ranganathan, V. Goode, and A. Ramaprasad, "Managing the transition to bricks and clicks," Communications of the ACM, vol.46, no.12, pp.308-316, (2003)

[6] J. W. Taylor, “The role of risk in consumer behavior," Journal of Marketing, vol.38, no.2, pp.54-60

[7] S. L. Jarvenpaa, N. Tractinsky, and M. Vitale, "Consumer trust in an internet store," Information Technology and Management, vol.1, no.1/2, pp.45-71, (2000)

[8] P. Paclou, "Consumer acceptance of electronic commerce: Integrating trust and risk with the technology acceptance model," International Journal of Electronic Commerce, vol.17, no.3, pp.101-134, (2003)

[9] G. L. Urban, A. Cinda, and L. Antonio, "Online trust: State of the art, new frontiers, and research potential," Journal of Interactive Marketing, vol.23, no.2, pp.179-190, (2009)

[10] A. Beldad, M. D. Jong, and M. Steehouder, "How shall I trust the faceless and the intangible? A literature review on the antecedents of online trust," Computers in Human Behavior, vol.26, no.5, pp.857-869, (2010)

[11] D. H. Mcknight and N. L. Chervany, "What trust means in e-commerce customer relationships: An interdisciplinary conceptual typology," International Journal of Electron Commerce, vol.6, no.2, pp.35-53, (2002)

[12] K. J. Stewart, “Trust transfer on the world wide web," Organization Science, vol.14, no.1, pp.5-17, (2003)

[13] H. H. Kuan and G. W. Bock, "Trust transference in brick and click retailers: An investigation of the beforeonline-visit phase,” Information and Management, vol.44, no.2, pp.175-187, (2007)

[14] K. C. Lee, I. Kang, and D. H. Mcknight, "Transfer from offline trust to key online perceptions: an empirical study," IEEE Transactions on Engineering Management, vol.54, no.4, pp.729-740, (2007)

[15] G. W. Bock, J. Lee, and H. H. Kuan, "The progression of online trust in the multi-channel retailer context and the role of product uncertainty, Decision Support Systems, vol.53, no.1, pp.97-107, (2012)

[16] W. J. Van Schijndel and J. Dinwoodie, "Congestion and multimodal transport: A survey of cargo transport operator in the Netherland," Transport Policy, vol.7, no.4, pp.231-241, (2000)

[17] F. Zhang, D. M. Johnson, and J. Wang, "Integrating multimodal transport into forest-delivered biofuel supply chain design,” Renewable Energy, vol.93, pp.58-67, (2016)

[18] Y. J. Seo, F. Chen, and X. Y. Roh, "Multimodal transportation: The case of laptop from Chongqing in China to Rotterdam in Europe," The Asian Journal of shipping and logistics, vol.33, no.3, pp.155-165, (2017)

[19] T. Zeng, D. Hu, and G. Huang, "The transportation mode distribution of multimodal transportation in automotive logistics," Procedia-Social and Behavioral Sciences, vol.96, pp.405-417, (2013)

[20] P. D. Larson, “The economic transportation quantity,” Transportation Journal, vol.28, no.2, pp.43-48

[21] C. Dong, S. Transchel, and K. Hoberg, “An inventory control model for modal split transport: A tailored basesurge approach,” European Journal of Operational Research, vol.264, no.1, pp.89-105, (2018)

[22] U. Venkatadri, K. S. Krishna, and M. A. Ulku, "On physical internet logistics: Modeling the impact of consolidation on transportation and inventory costs," IEEE Transactions on Automation Science and Engineering, vol.13, no.4, pp.1517-1527, (2016) 